\title{
PENGGABUNGAN BUMN SEKTOR PERIKANAN : STRATEGI MEWUJUDKAN KINERJA BUMN YANG EFISIEN DAN EFEKTIF
}

\author{
Oleh: \\ Tenny Apriliani, Mira, Agus Heri Purnomo dan Tjahjo Tri Hartono*
}

\begin{abstract}
Kajian mengenai penggabungan Badan Usaha Milik Negara (BUMN) sektor perikanan bertujuan untuk mengkaji kinerja BUMN perikanan sebelum dan setelah dilakukannya kebijakan penggabungan terhadap 4 BUMN Perikanan di Indonesia. Penelitian ini dilakukan sejak bulan Januari hingga Desember tahun 2006. Tahapan penelitian meliputi pendeskripsian masalah dan perumusan pilihan kebijakankebijakan yang dilakukan secara deskriptif dan penilaian kinerja keuangan dengan menggunakan analisis rasio keuangan. Hasil penelitian ini diperoleh informasi mengenai kinerja BUMN perikanan sebelum penggabungan dan prediksi kinerja setelah adanya penggabungan. Secara umum, hasil analisis kinerja keuangan keempat BUMN sektor perikanan sebelum penggabungan menunjukkan kinerja buruk. Artinya, perusahaan kesulitan untuk memenuhi kewajiban/utang-utang jangka pendek maupun jangka panjangnya. Kinerja PT Perikanan Nusantara (hasil penggabungan empat BUMN perikanan) pada prinsipnya sangat bertumpu pada unit usaha yang sebelumnya diusahakan oleh PT PSB. Unit usaha ini memiliki bisnis utama (core bussiness) pada kegiatan penangkapan tuna. Disisi lain perkembangan hasil tangkapan ikan tuna yang dilakukan oleh PT. PSB sebagai salah satu satuan unit bisnis PT.Perikanan Nusantara justru mengalami penurunan dari tahun ke tahun. Dua opsi kebijakan yang perlu dipertimbangkan adalah Kebijakan Penguatan Status Hukum dan Kebijakan Pre-Restrukturisasi. Kebijakan yang diusulkan ini selanjutnya diharapkan menjadi landasan dalam mewujudkan langkah-langkah strategis yaitu: (i) Strategi Penajaman Fokus Bisnis; (ii) Strategi Perbaikan Skala Usaha; dan (iii) Strategi Penciptaan Core Competencies.
\end{abstract}

\section{Kata Kunci : Penggabungan, BUMN Sektor Perikanan, Strategi, Kebijakan}

\section{Abstract: The National State Enterprises of Fisheries Sector Merger : Strategy To Realizing Efficient And Effective Government Corporate Performance by Tenny Apriliani, Mira, Agus Heri Purnomo and Tjahjo Tri Hartono}

Research on merging of The National State Enterprises of Fisheries Sector aims to analyze the performance of government corporate on fisheries before and after the merging policy on four governments corporate in Indonesia. This research was conducted from January to December 2006. Methodology used was the problem description and formulation of policy options and followed by assessment of financial performance by financial ratio analysis. The result of the research was information on the performance of government corporate before and after the merger. In general, the financial performance of four governments corporate of fisheries working before merger was poor. The corporations have difficulties to pay short and long term debts. The performance of PT.Perikanan Nusantara (merged corporate of four $B U M N$ ), basically it was highly converged on business unit of PT.PSB. This unit has core business on tuna's capture, which experiencing a constant decreasing on its yield. Two policy options should be considered to improve the situation, they are: the law status improvement and pre-restructurization policy. These policies were expected to realize the strategic steps; (i) Sharpening the business focus, (ii) Fixing the business scale and (iii) Core competencies creation

\section{Keywords : Merger, National State Enterprises of Fisheries Sector, Strategy, Policy}

\footnotetext{
* Peneliti Pada Balai Besar Riset Sosial Ekonomi Kelautan dan Perikanan, BRKP-DKP.

JI. KS TUBUN Petamburan VI Slipi Jakarta 10260. Telp. (021) 53650159
} 


\section{PENDAHULUAN}

Undang-undang Dasar 1945 mengamanatkan bahwa pelaku ekonomi nasional terdiri dari tiga bentuk usaha yaitu swasta, Badan Usaha Milik Negara (BUMN) dan koperasi. Konstitusi memaklumatkan bahwa di Indonesia terdapat perusahaanperusahaan yang dimiliki negara atau BUMN disamping usaha swasta dan koperasi. Definisi BUMN dalam UU No. 19 tahun 1993 adalah badan yang seluruh atau sebagian besar modalnya dimiliki oleh negara melalui penyertaan secara langsung yang berasal dari kekayaan negara yang dipisahkan. Terdapat 3 (tiga) bentuk BUMN yaitu Perusahaan Perseroan, Perusahaan Perseroan Terbuka dan Perusahaan Umum, ketiga bentuk BUMN ini dibedakan berdasarkan kepemilikan modal (persentase pemegang saham dan tujuan usaha) untuk mengejar keuntungan atau untuk kemanfaatan umum atau keduanya.

Dalam Master Plan BUMN tahun 2002 2006, BUMN di Indonesia dibagi kedalam 37 kelompok Badan Usaha, kelompok perikanan merupakan salah satu kelompok Badan Usaha didalam Master Plan BUMN tersebut dengan jumlah BUMN sebanyak 4 BUMN. Upaya atau langkah-langkah strategis pemerintah berdasarkan Master Plan BUMN Tahun 2002 2006 untuk meningkatkan kinerja BUMN di sektor perikanan adalah dengan menggabungkan BUMN-BUMN sektor perikanan yang ada kedalam dua BUMN yang bergerak dibidang penangkapan dan pengolahan (KepMen BUMN No. KEP/93/MMBU/2002). Langkah strategis tersebut sudah mulai dirintis sejak tahun 1998 melalui Peraturan Pemerintah No.21 Tahun 1998 tentang Pembubaran Perusahaan Umum (Perum) Perikanan Maluku, Penggabungan Perusahaan Persero (Persero) PT Perikani, Perusahaan Perseroan (Persero) Tirta Raya Mina dan Perusahaan Perseroan (Persero) PT Perikanan Samodra Besar ke dalam Perusahaan Perseroan (Persero) PT Usaha Mina serta penambahan pernyertaan modal negara Republik Indonesia ke dalam modal saham Perusahaan Persero (Persero) PT Usaha Mina.

Pada awal penggabungan, aktivitas usaha maupun administratif perkantoran pada beberapa BUMN perikanan berjalan tidak normal atau bahkan terhenti. Kondisi ini diakibatkan karena adanya bencana alam maupun kerusuhan di kantor-kantor cabang perusahaan. Nilai hutang yang tinggi, asset yang rendah serta minimnya sumber pendapatan perusahaan merupakan permasalahan yang dihadapi oleh pihak direksi PT. Perikanan Nusantara (Persero) hasil penggabungan 4 (empat) BUMN perikanan. Oleh karena itu perlu dikaji kembali apakah penggabungan 4 BUMN perikanan merupakan kebijakan yang tepat untuk meningkatkan kinerja BUMN perikanan atau justru akan memperburuk kinerja. Kajian teknis dan finansial dilakukan untuk menghasilkan rekomendasi perbaikan kebijakan revitalisasi BUMN perikanan untuk mencapai kinerja BUMN perikanan yang efisien dan efektif.

\section{METODE}

\section{Lokasi dan Waktu Riset}

Kegiatan riset ini dilakukan pada tahun 2006 dengan lokasi penelitian adalah Jakarta, Surabaya dan Bali. Kriteria lokasi adalah letak kantor pusat (Jakarta) dan kantor cabang BUMN hasil penggabungan atau PT Perikanan Nusantara (Surabaya dan Bali). Pemilihan kantor cabang didasarkan pada unit usaha yang secara finansial dan teknis masih berlangsung dan berpotensi sebagai unit usaha yang mendukung terwujudnya kinerja BUMN yang baik.

\section{Jenis dan Sumber Data}

Jenis data yang digunakan adalah data primer dan data sekunder. Data primer adalah persepsi dan aspirasi tentang arti strategis keberadaan BUMN sektor perikanan bagi peningkatan kesejahteraan masyarakat. Data primer bersumber dari manajemen 
BUMN setelah penggabungan (PT Perikanan Nusantara) dan para pemangku kepentingan BUMN (Menneg BUMN dan Ditjen P2HP DKP).

Data sekunder adalah laporan-laporan yang terkait dengan kinerja keuangan BUMNBUMN sektor perikanan sebelum penggabungan, prediksi kinerja keuangan BUMN sektor perikanan setelah penggabungan, faktor lingkungan eksternal (iklim investasi dan berusaha serta potensi SDI) dan faktor internal (teknis dan status hukum). Data sekunder bersumber dari laporan-laporan keuangan BUMN-BUMN terkait, laporan-laporan riset terdahulu yang terkait dengan tujuan dan sasaran riset.

\section{Metode Pengumpulan dan Analisis Data}

Data primer dikumpulkan melalui wawancara tidak terstruktur menggunakan panduan pertanyaan dengan pihak manajemen PT PN dan pihak-pihak yang mewakili instansi pemerintah yang terkait dengan pengelolaan BUMN (Menneg BUMN dan Departemen Kelautan dan Perikanan). Data sekunder dikumpulkan melalui penelusuran literatur di perpustakaanperpustakaan institusi riset dan pihak-pihak terkait.

Terkait dengan dampak kebijakan revitalisasi BUMN sektor perikanan melalui penggabungan empat BUMN menjadi satu BUMN maka analisis data pada prinsipnya mencakup:

a. Mendeskripsikan masalah: Dalam tahap ini dilakukan: (i) deskripsi masalah yang menjadi fokus analisis kebijakan; (ii) menampilkan data yang mencerminkan isu strategis; (iii) memfokuskan dan menggarisbawahi masalah dalam konteksnya secara spesifik termasuk mendiskusikan sebab dan akibat dari masalah tersebut; (iv) membangun kerangka pilihan kebijakan atas dasar argumen secara komprehensif.

b. Merumuskan pilihan-pilihan kebijakan: Membangun kerangka analisis dan evaluasi alternatif kebijakan dalam rangka merumuskan alternatif kebijakan. Pilihan kebijakan bersandar pada kaidah-kaidah: (i) menggarisbawahi, mengevaluasi dan membandingkan alternatif-alternatif kebijakan; (ii) membangun argumen yang meyakinkan terhadap alternatif kebijakan yang terbaik; (iii) memfokuskan pada sebuah keputusan yang dibuat; (iv) menjelaskan strategi yang memudahkan implementasi opsi kebijakan; (v) membangun kaitan yang jelas dan koheren dengan kesimpulan dan rekomendasi.

Aspek finansial dianalisis melalui penilaian kinerja keuangan dengan menggunakan analisis rasio keuangan (Hernanto, 1998; Sisdjatmiko, 1990; Riyanto, 1995) meliputi rasio likuiditas (rasio lancar/current ratio dan rasio kas/cash ratio) dan rasio solvabilitas (Rasio Kewajiban Jangka Panjang atas modal/Debt to Equity Ratio).

a. Likuiditas

- Current Ratio $=\frac{\text { Aktiva Lancar }}{\text { Kewajiban Lancar }} \times 1$ kali

Jika nilai Current Ratio $>1$,

secara umum kondisi likuiditas baik.

- Cash Ratio $=\frac{\text { Kas }+ \text { Surat Berharga }}{\text { Kewajiban Lancar }} \times 1$ kali

Jika nilai Cash Ratio semakin besar menunjukkan kondisi likuiditas semakin baik.

b. Leverage - Debt to Equity Ratio $=\frac{\text { Total Kewajiban }}{\text { (DER) }} \times 1$ kali

Jika nilai $D E R$ semakin kecil menunjukkan semakin baik tingkat keamanan usaha.

Rasio likuiditas bertujuan untuk mengetahui kemampuan perusahaan dalam membayar kewajiban-kewajiban jangka pendeknya, sedangkan rasio solvalibitas digunakan untuk memberikan gambaran mengenai kemampuan perusahaan dalam 
memenuhi kewajiban jangka panjang.

\section{HASIL DAN PEMBAHASAN}

\section{Gambaran Umum BUMN Perikanan Sebelum Penggabungan}

\section{Lini Usaha BUMN Sektor Perikanan}

Pada awal berdirinya, empat BUMN di sektor perikanan memiliki lini usaha yang beragam. Keragaman lini usaha tersebut dilatarbelakangi ragam industri di sektor perikanan mulai dari hulu ke hilir juga sangat beragam. Keragaman lini usaha empat BUMN sektor perikanan sebelum digabung tergambar pada data yang tersaji pada Tabel 1 .

Diantara keempat BUMN tersebut hanya PT. PSB yang melaksanakan aktivitas usahanya secara normal. Dari pengamatan di dua cabang PT PSB, yaitu di Benoa dan

Tabel 1. Lini Usaha BUMN Sektor Perikanan (Sebelum Penggabungan) di Indonesia, 2002

Table 1. Major Bussines of National State Enterprises of Fisheries Sector (Before Merger) in Indonesia, 2002

\begin{tabular}{|c|c|c|}
\hline No. & $\begin{array}{c}\text { BUMN di Sektor Perikanan/ } \\
\text { National State Enterprises of } \\
\text { Fisheries Sector }\end{array}$ & Lini Usahal Major Bussines \\
\hline 1. & $\begin{array}{l}\text { PT. Perikanan Samudera } \\
\text { Besar }\end{array}$ & $\begin{array}{l}\text { a) Perdagangan (Ekspor) Ikan Tuna Segar yang Berasal dari } \\
\text { Produk Sendiri/ Marketing (Export) Fresh Tuna from Own } \\
\text { Production } \\
\text { b) Penjualan Ikan Lokal yang Ekonomis Penting yang Berasal } \\
\text { dari Produk Sendiri, Berupa Produksi Ikan Tuna Segar./ } \\
\text { Local Marketing For High Commodities from Own } \\
\text { Production Such as Fresh Tuna } \\
\text { c) Penjualan Ikan Lokal Dari Kantor Cabang Benoa Bali/ Fish } \\
\text { Local Marketing from Branch Office in Benoa Bali } \\
\text { d) Penjualan Ikan Lokal dari Kantor Cabang Makassar/ Fish } \\
\text { Local Marketing from Branch Office in Makassar }\end{array}$ \\
\hline 2. & PT. Tirta Raya Mina & $\begin{array}{l}\text { a) Perdagangan Ikan di Dalam Negeri/ Domestic Fish } \\
\text { Marketing } \\
\text { b) Ekspor Ikan /Fish Export } \\
\text { c) Produksi dan Penjualan Es Balok/Production and Ice Block } \\
\text { Marketing } \\
\text { d) Penjualan Jasa Bengkel, Galangan dan Angkutan/ Marketing } \\
\text { Workshop Services, Dock Yard and Tranportation }\end{array}$ \\
\hline 3. & PT Perikani & $\begin{array}{l}\text { a) Pembelian Ikan/ Fish Purchasing } \\
\text { b) Pengolahan Ikan/ Fish Processing } \\
\text { c) Penjualan Ikan/ Fish Selling } \\
\text { d) Penjualan Jasa Sarana dan Prasarana / Marketing } \\
\text { Services For Facilities and Basic Facilities } \\
\text { e) Kegiatan Usaha Lainnya di Bidang Perikanan/ Others } \\
\text { Fisheries Bussines }\end{array}$ \\
\hline 4. & PT. Usaha Mina & $\begin{array}{l}\text { a) Penangkapan, Budidaya, Pengolahan, Perdagangan Ikan } \\
\text { dan Hasil Perairan Lainnya/ Capture, Fish Culture, } \\
\text { Processing, Fih and Other Fishery Commodity Marketing } \\
\text { b) Galangan Kapal, Jasa Dok, Perbengkelan dan } \\
\text { Refregerasi Perikanan/ Dock Yard, Docking Services, } \\
\text { Workshop and Fishery Refrigeration } \\
\text { c) Industri dan Perdagangan Bahan-Bahan, Alat-Alat } \\
\text { Perikanan Dalam Arti Seluas-Luasnya/ Industry and } \\
\text { Marketing Material, Fishery Appliances } \\
\text { d) Konsultan dan Pembangunan Unit Usaha Perikanan/ } \\
\text { Consultant and Fisheries Unit Bussines Developer }\end{array}$ \\
\hline
\end{tabular}

Sumber: Revitalisasi Aspek Teknis Usaha-Usaha Perikanan, PK2P-DKP, 2002.

Source : Revitalization Technical Aspect of Fishery Bussines, PK2P-DKP, 2002 
Surabaya, tampak jelas kegiatan produksi masih berjalan normal diantaranya pada kantor cabang Benoa dengan lini usaha penangkapan, pengolahan dan pemasaran, perdagangan hasil pembelian, jasa coldstorage dan processing ikan tuna segar dan kantor Surabaya adalah jasa dok, bengkel, dan perbaikan kapal sampai ukuran 150 GT. Oleh karena itu, kedua lokasi ini dijadikan sebagai lokasi kegiatan verifikasi bagi operasional kantor cabang yang masih berjalan normal. Meskipun demikian, normalnya kegiatan yang dijalankan di kedua cabang tersebut patut diwaspadai keberlanjutannya. Sejak didirikan hingga saat ini belum pernah dilaksanakan penggantian sarana dan prasarana produksi. Dengan demikian teknologi yang digunakan kalah bersaing dengan teknologi perusahaan pesaing yang jauh lebih maju.

Sementara itu, berdasarkan kajian yang dilakukan Departemen Kelautan dan Perikanan pada tahun 2002 (PK2P, 2002), diketahui bahwa lini usaha yang dijalankan oleh PT. Usaha Mina hampir mirip dengan yang dilakukan oleh PT. PSB. Kegiatan BUMN ini mencakup kegiatan penangkapan, pengolahan, perdagangan, jasa cold storage dan perbengkelan. Perbedaan dengan PT PSB terletak pada pola produksi dalam kegiatan penangkapan. Dalam hal ini PT. Usaha Mina menerapkan Pola Inti Plasma. Berdasarkan pola tersebut, sarana dan prasarana yang dimiliki oleh PT.Usaha Mina adalah pabrik es, cold storage, unit prosesing, dan galangan kapal. Saat ini, usaha yang dilakukan oleh PT Usaha Mina yang masih aktif adalah di cabang Gorontalo. Kondisi memprihatinkan dialami di lokasi Sorong. Di kantor cabang tersebut sarana dan prasarana sudah tidak dapat difungsikan lagi akibat kerusuhan yang terjadi. Sedangkan untuk cabang Bacan dan Ambon perlu dilakukan perbaikan,

Sarana dan prasarana yang dimiliki oleh PT. Perikani Aertembaga meliputi tujuh unit kapal yang difungsikan sebagai kapal pengangkut dan penampungan, namun kondisinya yang sudah berumur tua mengakibatkan secara ekonomis kapal ini sudah tidak dapat difungsikan lagi. Pabrik es, unit prosesing, cold storage dan perbengkelan yang saat ini kondisinya membutuhkan perbaikan karena berumur tua. Sarana dan prasarana yang dimiliki sesuai dengan lini usaha yang dijalankan meliputi pengolahan, perdagangan, jasa cold storage dan perbengkelan (docking).

PT. Tirtaraya Mina merupakan perusahaan yang bergerak di bidang pengolahan dan perdagangan serta jasa cold storage dan perbengkelan. Sarana dan prasarana yang dimiliki meliputi unit pengolahan, cold storage, pabrik es dan galangan kapal. Berdasarkan hasil kajian (Pengolahan dan Pemasaran Hasil Perikanan (P2HP), 2002. Diketahui bahwa kondisi sarana dan prasarana yang pada saat ini membutuhkan perbaikan adalah di cabang Pekalongan. Adapun sarana dan prasarana di cabang Tanjung Karimun sebagian tidak dapat difungsikan lagi karena kerusakan yang cukup berat. Tabel 2 secara rinci menunjukkan kepemilikan sarana dan prasana setiap cabang serta kondisinya pada tahun 2005.

Beberapa penyebab terhentinya aktivitas administrasi maupun usaha BUMN perikanan (Tabel 3) dikarenakan sarana dan prasarana operasional usaha telah rusak parah atau memerlukan perbaikan. Kegiatan usaha sebagian besar terhenti akibatnya perusahaan tidak memiliki pendapatan usaha sedangkan biaya gaji karyawan harus dikeluarkan, hal inilah yang menyebabkan menumpuknya utang usaha. Diantara empat BUMN yang digabungkan hanya dua unit usaha yang masih berjalan normal yaitu PT. Perikanan Samodera Besar dan PT. Tirta Raya Mina. Kedua unit usaha inilah yang dapat dijadikan sebagai awal modal kerja usaha BUMN Perikanan pada awal penggabungan.

Sebagai gambaran, kondisi usaha salah satu cabang PT. Perikanan Samodra Besar sebelum penggabungan berjalan normal baik 


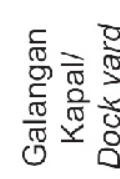

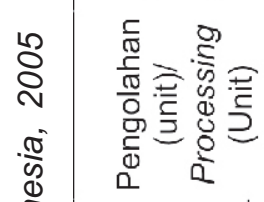

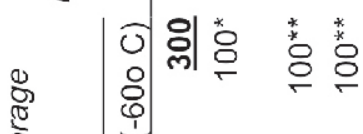

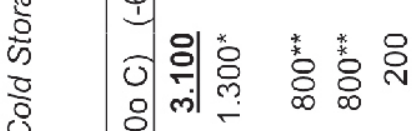

ช

Fl $\stackrel{*}{m} \stackrel{*}{m} \stackrel{*}{*} \sim N \quad N \quad \stackrel{*}{*}$

㐫衷

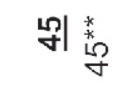

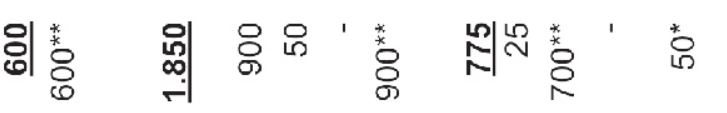

这施

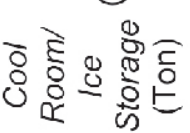

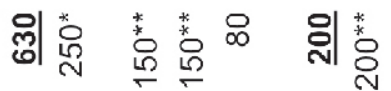

이 응 ' ' $\stackrel{*}{*}$

w

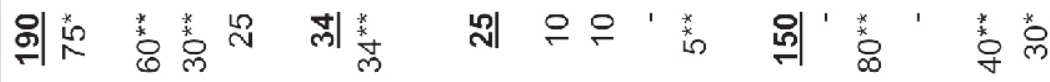

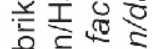

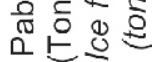

产

()

菏

위ํ은 은 옹

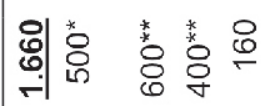

잇ํㅇㅇㅇ

임. 옹 응

윔유융유 융

ॠ.

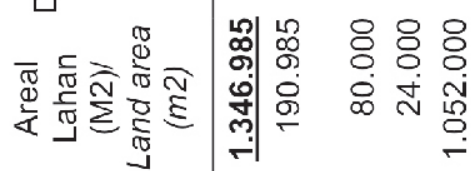

힣응

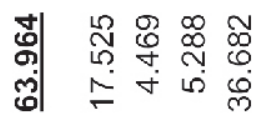

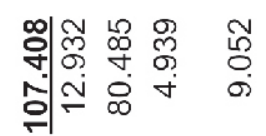

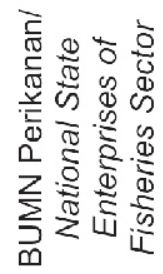

ㅇ

$\frac{1}{\frac{0}{\sigma}} \frac{0}{\frac{0}{\sigma}}$
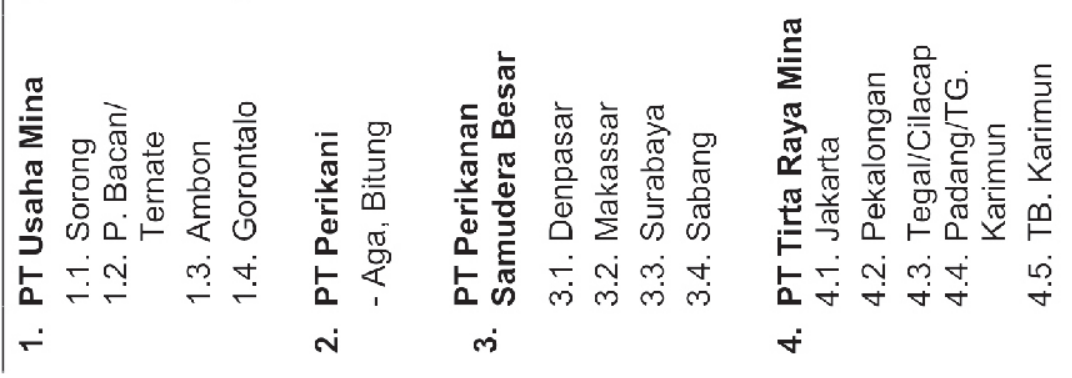

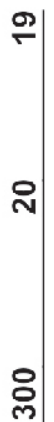

유

ผึ

$\stackrel{4}{4}$

욤

ஓ्ले

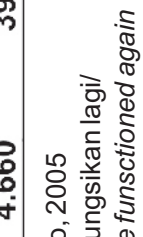

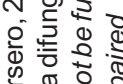

ㅇำ

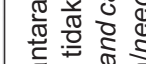

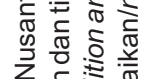

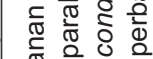

กิ

ปั่

กิ

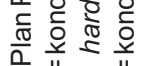

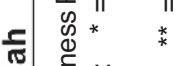

든 $\mathscr{D}^{*}{ }^{*}$ 
Tabel 3. Kondisi Kegiatan Kantor Cabang Pada Awal Penggabungan BUMN Perikanan di Indonesia, 2005

Table 3. Condition Of Branch Office Activities On The Early Stage of Merger of National State Enterprises of Fisheries Sector in Indonesia, 2005

\begin{tabular}{|c|c|c|c|}
\hline NO & $\begin{array}{c}\text { KANTOR CABANG/ } \\
\text { Branch Office }\end{array}$ & $\begin{array}{c}\text { AKTIVITAS ADMINISTRASI/ } \\
\text { Administration Activity }\end{array}$ & $\begin{array}{l}\text { AKTIVITAS USAHA/ } \\
\text { Bussines Activity }\end{array}$ \\
\hline \multirow[t]{5}{*}{$\mathbf{I}$} & UNIT USAHA MINA & & \\
\hline & $\begin{array}{l}\text { - Cabang Sorong/ } \\
\text { Sorong Branch }\end{array}$ & Berhenti/ Suspended & Berhenti / Suspended \\
\hline & $\begin{array}{l}\text { - Cabang Ambon/ } \\
\text { Ambon Branch }\end{array}$ & Tidak Normal / Not Normal & Tidak Normal/ Not normal \\
\hline & $\begin{array}{c}\text { - Cabang Bacan/ } \\
\text { Bacan Branch }\end{array}$ & Berhenti / Suspended & Berhenti / Suspended \\
\hline & $\begin{array}{l}\text { - Cabang Gorontalo/ } \\
\text { Gorontalo Branch }\end{array}$ & Berhenti / Suspended & $\begin{array}{l}\text { Dikelola Pemda/ Organized by } \\
\text { Local Government }\end{array}$ \\
\hline \multirow[t]{5}{*}{ II } & UNIT TIRTA RAYA MINA & & \\
\hline & $\begin{array}{l}\text { - Cabang Jakarta/ } \\
\text { Jakarta Branch }\end{array}$ & Berjalan Normal/ Normal & Berhenti / Suspended \\
\hline & $\begin{array}{l}\text { - Cabang Tegal/ } \\
\text { Tegal Branch }\end{array}$ & Berjalan Normal / Normal & Berjalan Normal \\
\hline & $\begin{array}{l}\text { - Cabang Pekalongan/ } \\
\text { Pekalongan Branch }\end{array}$ & Berhenti / Suspended & Berhenti / Suspended \\
\hline & $\begin{array}{l}\text { - Cabang Padang/ } \\
\text { Padang Branch }\end{array}$ & Berjalan Normal / Normal & Tidak Normal / Not Normal \\
\hline \multirow[t]{5}{*}{ III } & \multicolumn{3}{|c|}{ UNIT PERIKANAN SAMUDERA BESAR } \\
\hline & $\begin{array}{l}\text { - Cabang Surabaya/ } \\
\text { Surabaya Branch }\end{array}$ & Berjalan Normal / Normal & Berjalan Normal / Normal \\
\hline & $\begin{array}{l}\text { - Cabang Benoa, Bali/ } \\
\text { Benoa Branch, Bali }\end{array}$ & Berjalan Normal / Normal & Berjalan Normal / Normal \\
\hline & $\begin{array}{l}\text { - Cabang Makassar/ } \\
\text { Makassar Branch }\end{array}$ & Berjalan Normal / Normal & Berjalan Normal / Normal \\
\hline & $\begin{array}{l}\text { - Cabang Sabang/ } \\
\text { Sabang Branch }\end{array}$ & Berjalan Normal / Normal & Berhenti / Suspended \\
\hline IV & $\begin{array}{l}\text { UNIT AGA / PERIKANI } \\
\text { - Cabang Bitung/ } \\
\text { Bitung Branch } \\
\end{array}$ & Tidak Normal / Not Normal & Tidak Normal / Not normal \\
\hline
\end{tabular}

Sumber/ Source: Bussiness Plan, PT Perikanan Nusantara, 2005.

aktivitas administrasi maupun operasional. Sumberdaya manusia yang terampil serta kapal penangkap yang masih laik operasional merupakan salah satu pendukung masih berjalannya kegiatan usaha dengan baik. Cabang usaha di Benoa juga dilengkapi dengan sarana darat berupa Cold Storage: 900 ton, Pabrik Es: 20 ton, Ruang Processing, dermaga milik sendiri, bengkel dan perkantoran. Tersedianya modal kerja untuk menjalankan kegiatan usaha serta lokasi yang cukup strategis untuk kegiatan penangkapan maupun pemasaran ekspor dan lokal juga mendukung keberlangsungan kegiatan usaha pada cabang Benoa. Masih berjalannya usaha pada cabang Benoa diketahui melalui masih adanya pembelian ikan hasil kegiatan operasional pada berbagai pihak di dalam dan di luar negeri (Laporan Keuangan PT. Perikanan Samudera Besar (PT. PSB, 2004).

Gambaran lain pelaksanaan kegiatan usaha PT PSB yang masih berjalan normal 
adalah pada cabang Surabaya. Cabang Surabaya merupakan unit usaha yang difokuskan untuk kegiatan usaha perbengkelan. Cabang usaha Surabaya memiliki sarana galangan kapal (dock) dengan kemampuan sampai 300 GT. Tenaga yang tersedia juga mempunyai ketrampilan untuk menangani operasional sarana galangan kapal, ketersediaan sarana serta tenaga yang terampil merupakan pendukung masih berlangsungnya kegiatan usaha di cabang Surabaya.

\section{Kondisi Kesehatan BUMN Sektor Perikanan}

Hasil penelusuran literatur dan wawancara dengan stakeholder terkait (Menneg BUMN, 2006) menunjukkan bahwa hingga tahun 2005 (sebelum penggabungan), hanya PT PSB yang secara periodik menyusun dan melaporkan laporan keuangan yang telah diaudit oleh Kantor Akuntan Publik. Sesuai dengan aspek hukum (Kepmen BUMN No. 100/MBU/2002) tentang Penilaian Tingkat Kesehatan BUMN, kondisi kesehatan suatu BUMN hanya dapat dinilai berdasarkan hasil pemeriksaan akuntan terhadap perhitungan keuangan tahunan perusahaan yang bersangkutan. Nilai yang diberikan dinyatakan dengan kualifikasi "Wajar Tanpa Pengecualian" atau kualifikasi "Wajar Dengan Pengecualian" dari akuntan publik atau Badan Pengawas Keuangan dan Pembangunan. Berdasarkan peraturan pemerintah tersebut maka nilai-nilai rasio keuangan yang disajikan baru dianggap sebagai suatu asumsi terhadap kondisi perusahaan. Masih diperlukan suatu due-diligence yang dilakukan oleh akuntan publik untuk dapat mengetahui kondisi perusahaan yang sebenarnya.

Berdasarkan data yang diperoleh dari berbagai sumber (BUMN on-line dan Ditjen P2HP-DKP, 2006) diketahui kinerja atau kondisi kesehatan keuangan BUMN di sektor perikanan sebelum penggabungan menunjukkan kinerja keuangan BUMN-BUMN di sektor perikanan relatif buruk (Tabel 4). Artinya, perusahaan kesulitan untuk memenuhi kewajiban/utang-utang jangka pendek maupun jangka panjangnya.

Secara detail dapat diuraikan bahwa hasil analisis menunjukkan bahwa nilai rasio lancar PT Perikanan Samodra Besar (PT.PSB) sebesar 2,77. Nilai ini menunjukkan bahwa PT.PSB mampu menjamin setiap rupiah utang lancarnya dengan harta lancar. Hasil analisis

\section{Tabel 4. Rasio Likuiditas dan Solvabilitas BUMN Sektor Perikanan Sebelum Penggabungan di Indonesia, per Oktober 2005}

Table 4. Likuiditas and Solvabilitas Ratio of National State Enterprises of Fisheries Sector Before Merger in Indonesia, Per Oktober 2005

\begin{tabular}{lrrr}
\hline $\begin{array}{c}\text { BUMN Sektor Perikanan } \\
\text { (sebelum Penggabungan)/ }\end{array}$ & \multicolumn{2}{c}{$\begin{array}{c}\text { Nilai Rasio Likuiditas/ } \\
\text { Value of Likuiditas Ratio }\end{array}$} & $\begin{array}{c}\text { Nilai Rasio Solvabilitas/ } \\
\text { Value of Solvabilitas Ratio }\end{array}$ \\
\cline { 2 - 4 } Fisheries Sector (before Merger) & $\begin{array}{c}\text { Nilai Rasio } \\
\text { Lancarl } \\
\text { Current Ratio }\end{array}$ & $\begin{array}{c}\text { Nilai Rasio } \\
\text { Kas/ } \\
\text { Cash Ratio }\end{array}$ & $\begin{array}{c}\text { Rasio Kewajiban Jangka } \\
\text { Panjang atas Modal/ } \\
\text { Debt to Equity Ratio }\end{array}$ \\
\hline PT. Perikanan Samudera Besar & 2,77 & 0,0821 & 85,78 \\
PT.Usaha Mina & 0,11 & 0,00002 & 726,44 \\
PT.Tirta Raya Mina & 0,37 & 0,0012 & 76,52 \\
PT.Perikani & 0,14 & 0,0023 & $1.427,87$ \\
\hline
\end{tabular}

Sumber : Kementerian Negara BUMN 2005 (Diolah)/

Source : Ministry of Government Corporate 2005 (Processed)

Keterangan: Belum diaudit oleh KAP/

Remark: have not been audited byPAO 
kinerja keuangan ketiga BUMN perikanan lainnya menunjukkan nilai ratio lancar $<1$ yaitu PT. Usaha Mina dengan rasio 0,11, PT. Tirta Raya Mina (PT.TRM) dengan nilai ratio 0,37 dan PT. Perikani dengan nilai ratio 0,14.

Nilai ratio lancar yang kurang dari 1 menunjukkan bahwa perusahaan gagal untuk membayar utang lancarnya yang sudah jatuh tempo dengan harta lancarnya. Umumnya angka dua banding satu (2:1) atau harta lancar dua kali lipat kewajiban jangka pendeknya dianggap cukup aman bagi keuangan perusahaan. Berdasarkan hasil analisis dengan menggunakan analisis rasio lancar terhadap kinerja keuangan diantara keempat BUMN sektor perikanan ternyata hanya 1 (satu) perusahaan yang kinerja keuangannya dianggap aman yaitu PT.PSB sedangkan ketiga perusahaan lainnya mengalami kesulitan untuk membayar utang jangka pendeknya.

Rasio kas menunjukkan uang tunai yang ada di tangan (cash on hand), yang ada di bank serta surat-surat berharga, baik dalam bentuk obligasi, saham dan sebagainya yang setiap waktu mudah dicairkan (dijual) menjadi uang kas (tunai). Berdasarkan analisis rasio kas, nilai rasio masing-masing BUMN sektor perikanan adalah PT.PSB 0,0821, PT. Usaha Mina 0,00002, PT. TRM 0,0012 dan PT. Perikani 0,0023. Diantara keempat BUMN Perikanan tersebut PT.PSB memiliki rasio kas yang paling tinggi dan PT. Usaha Mina dengan nilai terendah. Nilai ini menunjukkan bahwa kinerja keuangan berdasarkan rasio kas PT.PSB paling baik diantara ketiga BUMN sektor perikanan lainnya.

Rasio kewajiban jangka panjang atas modal/Debt to equity ratio bertujuan untuk melihat seberapa besarnya (\%) utang jangka panjang operasi dibandingkan dengan modal perusahaan. Nilai rasio untuk keempat perusahaan BUMN sektor perikanan cukup tinggi atau bahkan sangat tinggi, nilai rasio $\mathrm{PT}$. Perikani dan PT. Usaha Mina diatas 100\% menunjukkan bahwa kondisi utang jangka panjang perusahaan yang sangat besar dibandingkan modal yang dimiliki perusahaan hal ini merupakan keadaan yang perlu segera dibenahi.

Lebih lanjut, PT. TRM merupakan perusahaan BUMN perikanan dengan nilai DER paling rendah dibandingkan ketiga BUMN lainnya yaitu sebesar $76,52 \%$, nilai ini menunjukkan bahwa utang jangka panjang perusahaan masih bisa dibiayai dari modal perusahaan. Begitu pula halnya dengan PT.PSB nilai rasio sebesar $85,78 \%$ menunjukkan bahwa utang jangka panjang PT.PSB sebesar $85,78 \%$ modal perusahaan. Berdasarkan hasil analisis rasio kewajiban jangka panjang atas modal maka kinerja keuangan diantara keempat BUMN sektor perikanan PT.TRM lah yang dianggap paling aman dibandingkan ke tiga perusahaan lainnya.

Buruknya kinerja keuangan secara tidak langsung juga mencerminkan beratnya permasalahan bagi BUMN-BUMN sektor perikanan untuk dapat melaksanakan usahanya secara berkelanjutan. Pertimbangan terhadap kondisi saranaprasarana dan normalitas kegiatan serta dicerminkan oleh buruknya kinerja berdasarkan aspek finansial menjadi hal-hal yang diantaranya melatarbelakangi munculnya kebijakan penggabungan BUMN sektor perikanan.

\section{Prediksi Kondisi BUMN Setelah Penggabungan}

\section{Kinerja Keuangan BUMN Sektor Perikanan}

Tabel 5 menunjukkan kondisi keuangan BUMN sektor Perikanan setelah dilakukan penggabungan. Berdasarkan data yang masih belum menjalani proses audit dari KAP tersebut kinerja keuangan PT PN setelah penggabungan adalah sebagai berikut: rasio lancar 0,2491, rasio kas 0,0846, dan rasio solvabilitas $53,08 \%$ (Bussines Plan PT. Perikanan Nusantara, 2005). Nilai rasio 
Tabel 5. Kondisi Keuangan/Neraca Konsolidasi BUMN Sektor Perikanan Sesudah Penggabungan in Indonesia, 2005 (dalam juta rupiah)

Table 5. Financial Condition/ Balance Consolidation of National State Enterprises of Fisheries Sector After Merger in Indonesia, 2005 (million rupiah's)

\begin{tabular}{|c|c|c|c|c|c|c|}
\hline No & Uraian/ Description & $\begin{array}{c}\text { PT. Perikanan } \\
\text { Samudera Besar }\end{array}$ & $\begin{array}{c}\text { PT.Usaha } \\
\text { Mina }\end{array}$ & $\begin{array}{l}\text { PT.Tirta Raya } \\
\text { Mina }\end{array}$ & PT.Perikani & $\begin{array}{l}\text { Konsolidasi / } \\
\text { Consolidation }\end{array}$ \\
\hline \multirow[t]{6}{*}{ I } & $\begin{array}{l}\text { DEBET/ Debited } \\
\text { AKTIVA LANCAR/ } \\
\text { Cash Activa }\end{array}$ & & & & & \\
\hline & $\sim$ Kas dan Setara Kas/Cash & 12.198 & 98 & 57 & 43 & 12.397 \\
\hline & $\sim$ Piutang/Credit & 2.428 & 589 & 199 & 208 & 3.424 \\
\hline & Persediaan/Supply & 2.553 & 5.653 & 344 & 733 & 9.274 \\
\hline & $\begin{array}{l}\sim \text { Piutang lainnya / Other } \\
\text { Credit }\end{array}$ & 2.459 & 7.236 & 650 & 1.040 & 11.393 \\
\hline & $\begin{array}{l}\text { Jmlh Aktiva Lancar/ } \\
\text { Total Cash Asset }\end{array}$ & 19.638 & 13.576 & 1.250 & 2.024 & 36.488 \\
\hline \multirow[t]{4}{*}{ II } & $\begin{array}{l}\text { AKTIVA TETAPI } \\
\text { Fixed Activa }\end{array}$ & & & & & \\
\hline & $\sim$ Tanah/ Land & 69 & 668 & 367 & 3.073 & 4.177 \\
\hline & $\begin{array}{l}\text { Gedung \& Kontruksi/ } \\
\text { Building and Construction }\end{array}$ & 1.474 & 20.468 & 2.896 & 312 & 25.149 \\
\hline & Nilai Buku/Book Value & 10.257 & 10.286 & 1.991 & 3.573 & 26.107 \\
\hline \multirow[t]{2}{*}{ III } & $\begin{array}{l}\text { AKTIVA LAIN-LAIN/ } \\
\text { Other Activa }\end{array}$ & 151 & 41.982 & 2.413 & 190.411 & 44.736 \\
\hline & Jumlah Aktiva/ Total Activa & 30.046 & 65.844 & 5.695 & 5.787 & 107.372 \\
\hline \multirow[t]{4}{*}{ I } & $\begin{array}{l}\text { KREDIT/credited } \\
\text { PASSIVA LANCAR/ } \\
\text { Cash Passiva }\end{array}$ & & & & & \\
\hline & $\begin{array}{l}\text { Kewajiban Jangka } \\
\text { Pendek/Short Term Debt }\end{array}$ & 7.092 & 126.448 & 3.337 & 9.587 & 146.463 \\
\hline & $\begin{array}{l}\text { Kewajiban Jangka Panjang/ } \\
\text { Long Term Debt }\end{array}$ & 248 & 49.805 & 5.766 & & 55.818 \\
\hline & Jumlah Hutang/ Debt Total & 7.340 & 176.253 & 9.103 & 9.587 & 202.282 \\
\hline \multirow[t]{2}{*}{ II } & EQUITAS /Equity & 22.706 & (110.409) & $(3.408)$ & $(3.800)$ & (94.910) \\
\hline & $\begin{array}{l}\text { Jumlah Kewajiban \& } \\
\text { Equitas / } \\
\text { Total Obligation \& Equity }\end{array}$ & 30.046 & 65.844 & 5.695 & 5.787 & 107.372 \\
\hline
\end{tabular}

Sumber : Kementerian Negara BUMN 2005 (Diolah)

Source : Ministry of Government Corporate 2005 (Processed)

Keterangan: Belum diaudit oleh KAP

Remark: Have not been audited by KAP

tersebut menunjukkan bahwa kondisi keuangan PT PN setelah penggabungan masih mengkhawatirkan.

Perusahaan kesulitan untuk melunasi hutang jangka pendeknya hal ini ditunjukkan oleh nilai rasio lancar $<1$. Nilai persediaan kas perusahaan baik dalam bentuk uang tunai, surat-surat berharga dalam bentuk obligasi maupun saham menunjukkan posisi yang kurang aman karena nilainya masih $<1$, nilai ini menunjukkan bahwa persediaan kas perusahaan masih belum cukup untuk melunasi kewajiban jangka pendeknya. Rasio solvabilitas PT PN setelah penggabungan menunjukkan nilai yang kurang baik. Nilai rasio solvabilitas sebesar $53,08 \%$ menunjukkan bahwa $53,08 \%$ total harta perusahaan didanai dari utang jangka panjangnya.

Belum terauditnya laporan keuangan dan kondisi keuangan yang tidak sehat berdasarkan laporan keuangan tersebut, RUPS Luar Biasa menugaskan anggota 


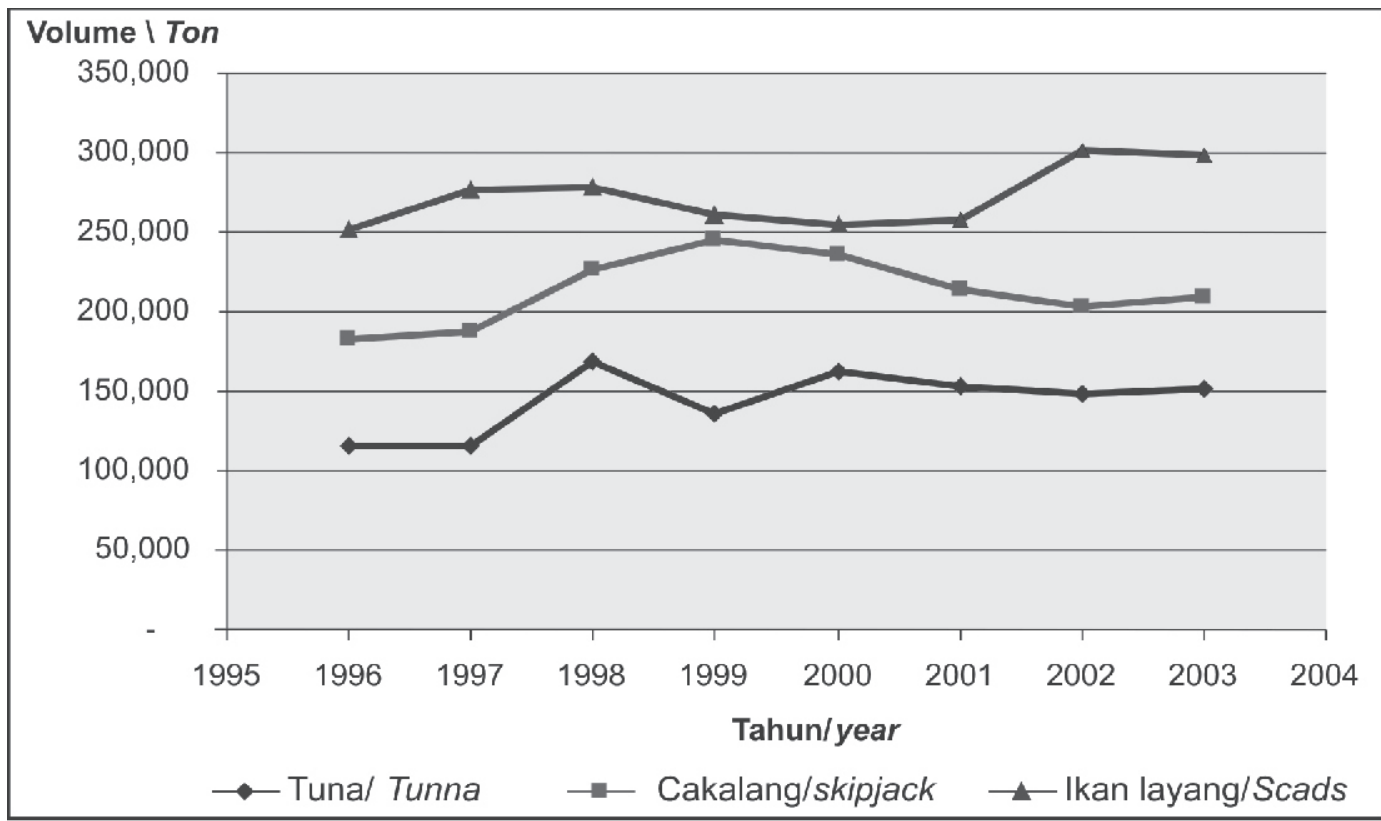

Sumber :

Statistik Perikanan Tangkap Indonesia 2003, Direktorat Jenderal Perikanan Tangkap - DKP, 2005 dalam Balai Besar Riset Sosial Ekonomi Kelautan dan Perikanan, 2006

Source : Statistic of Indonesia Capture Fisheries 2003, Directorate General of Capture Fisheries-Marine and Fisheries Ministry, 2005 in Center for Marine and Fisheries Socio-Economic Research, 2006

Gambar 1. Produksi Ikan Tuna, Cakalang dan Layang di Indonesia ,1996 - 2003

Figure 1. Production of Tunna, Skipjack and Scads in Indonesia, 1996 - 2003

Direksi PT. Usaha Mina (Persero) hasil penggabungan untuk melaksanakan empat langkah, mencakup: (i) menyusun neraca penutup dan neraca pembukaan yang telah memenuhi standar audit sehingga dapat menjadi landasan untuk langkah-langkah berikutnya; (ii) menyusun program strategi pengembangan perusahaan ke depan yang bilamana diperlukan untuk hal tersebut maka Direksi dapat menggunakan konsultan dengan biaya yang wajar; (iii) mencari mitra strategi/investor untuk kerjasama; dan (iv) menyelesaikan perubahan Anggaran Dasar PT. Usaha Mina (Persero) hasil penggabungan.

\section{Kendala Pengembangan BUMN Sektor Perikanan}

Hasil kajian terhadap kinerja keuangan, yang diperoleh dari laporan keuangan yang belum teraudit, menunjukkan kinerja PT PN sangat bertumpu pada unit usaha yang sebelumnya diusahakan oleh PT PSB. Unit usaha ini memiliki bisnis utama (core bussiness) pada kegiatan penangkapan terutama tuna.

Kondisi bisnis utama dari PT PSB ini menghadapi kendala, dari tahun ke tahun perkembangan hasil tangkapan ikan tuna mengalami penurunan. Hasil tangkapan ikan tuna per 100 mata pancing yang diperoleh pada tahun 2005 menurun hingga 80\% dibandingkan tahun 1978 seperti yang ditampilkan pada Gambar 1. Sebaliknya, dalam periode yang relatif sama, data statistik menunjukkan bahwa produksi tuna, cakalang dan layang secara mengalami kenaikan dari tahun 1996 hingga 2003 (BBRSE, 2006). Rata-rata kenaikan per tahun adalah sebesar $6 \%$ untuk ikan tuna, 4\% untuk ikan cakalang 


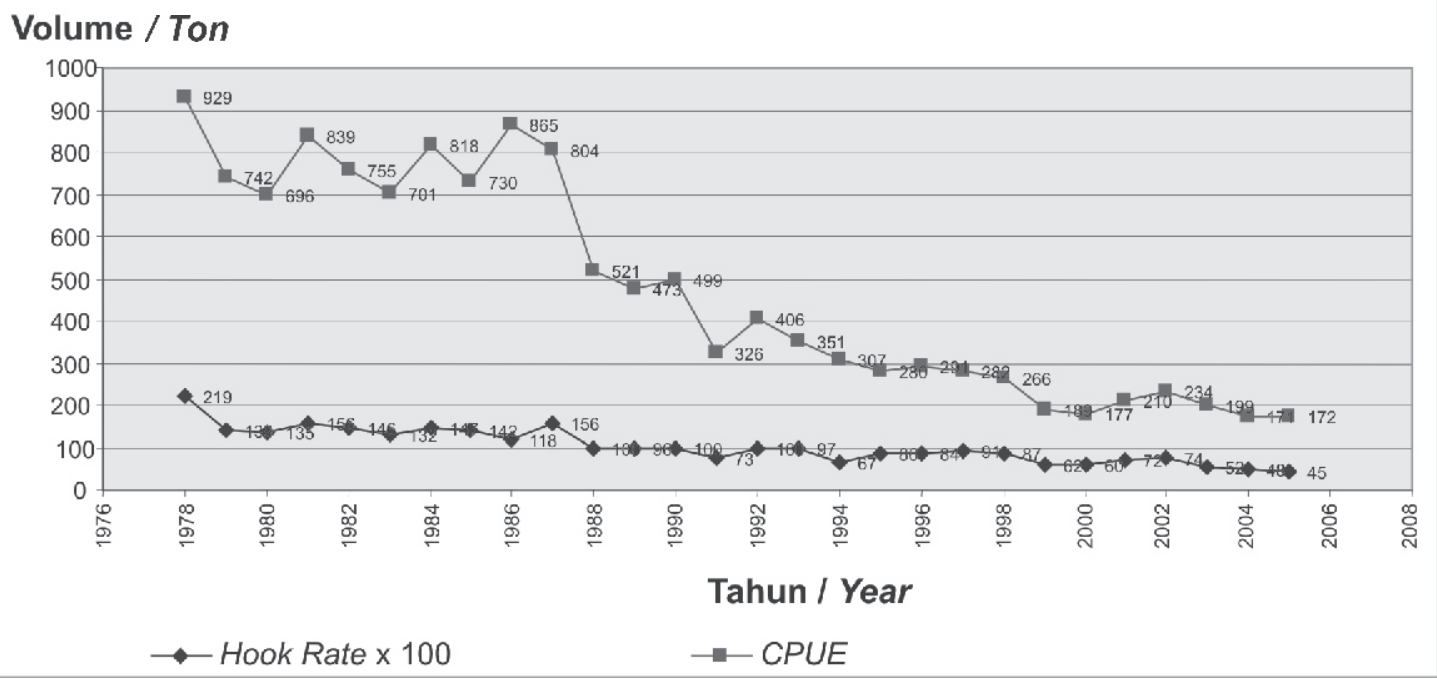

Sumber/Source: PT. Perikanan Samudera Besar, Agustus 2005

Keterangan:

Hook Rate $=$ Hasil Tangkapan Ikan Tuna per 100 Mata Pancing (satuan volume = ekor)

CPUE $=$ Catch Rate Per Unit Effort (satuan volume $=\mathrm{Kg}$ )

Remark:

Hook Rate = Tunna Capture Per 100 Hooks (volume = fish)

CPUE = Catch Rate Per Unit Effort (volume $=\mathrm{Kg}$ )

\section{Gambar 2. Perkembangan Tangkapan Ikan Tuna Tahun di Indonesia, 1978-2005}

Figure 2. Growth of Tuna's Capture In Indonesia, 1978 - 2005

dan $8 \%$ untuk ikan layang (Gambar 2).

Tercatat beberapa hal yang menyebabkan terjadinya penurunan hasil tangkapan yang cukup signifikan, yaitu: (i) Adanya kenaikan jumlah armada penangkapan baik kapal yang berasal dari dalam maupun kapal asing dan (ii) Kapal penangkap yang digunakan secara teknis umurnya sudah tua serta teknologi yang digunakan pun kalah bersaing dengan armada kapal milik pesaing yang lebih baru dan canggih.

Secara umum beberapa kendala yang dihadapi oleh BUMN sektor perikanan pada awal penggabungan untuk menghasilkan kinerja yang efektif dan efisien dibedakan menjadi kendala teknis dan kendala non teknis (ekonomis dan hukum). Kendala teknis yang dihadapi meliputi: (1) Tidak berfungsinya beberapa aset perusahaan yang mengakibatkan aktivitas usaha tidak berjalan normal; (2) Meningkatnya jumlah armada penangkapan (lokal maupun asing) sehingga mengakibatkan iklim kompetisi semakin tinggi; dan (3) Teknologi yang digunakan kalah bersaing dengan kompetitor yang lebih baru dan canggih. Sedangkan kendala non teknis terdiri dari menumpuknya hutang jangka pendek maupun jangka panjang yang harus segera dilunasi oleh manajemen perusahaan (kendala ekonomis) serta belum pastinya status hukum BUMN perikanan hasil penggabungan (kendala hukum). Kendala yang bersifat teknis maupun non teknis tersebut harus segera ditangani oleh pihak manajemen yang baru agar penggabungan 4 BUMN Perikanan dapat menghasilkan kinerja yang efektif dan efisien. 
Kebijakan dan Langkah Aksi-Strategis

\section{Revitalisasi BUMN Sektor Perikanan}

Berdasarkan hasil analisis terhadap kondisi BUMN sektor perikanan sebelum penggabungan (empat BUMN) dan sesudah penggabungan (PT Perikanan Nusantara) maka dapat dirumuskan beberapa opsi kebijakan yang dapat disarankan sebagai alternatif dalam upaya revitalisasi BUMN sektor perikanan sehingga mampu menjadi BUMN komersial yang efisien dan efektif.

Pada saat ini dapat diasumsikan bahwa BUMN sektor perikanan belum dikelola dengan baik. Secara sistematis dan sesuai dengan arahan tentang reformasi BUMN yang muktahir maka diperlukan beberapa opsi kebijakan alternatif yang secara krusial dan sesegera mungkin diimplementasikan dalam rangka upaya meningkatkan kinerja BUMN sektor perikanan. Opsi kebijakan yang dapat dipertimbangkan untuk diimplementasikan yaitu :

\section{Kebijakan Penguatan Status Hukum}

Dalam paparan di bagian sebelumnya telah diketahui bahwa hingga kini status hukum PT Perikanan Nusantara (PT PN) sebagai BUMN sektor perikanan hasil penggabungan masih belum tuntas. Kepastian status hukum sangat diperlukan agar seluruh kegiatan usaha PT PN berjalan sesuai dengan ketentuan peraturan perundangan yang berlaku.

2. Kebijakan Pre-Restrukturisasi

Kebijakan pre-restrukturisasi adalah Direksi PT PN (dalam proses hukum) melakukan penyusunan neraca penutup dan neraca pembukaan yang dihasilkan dari proses audit akuntan yang seksama. Hal ini diperlukan untuk mendapatkan suatu gambaran tentang kondisi kesehatan perusahaan yang selanjutnya menjadi bahan penyusunan kebijakan restrukturisasi.

3. Kebijakan restrukturisasi

Sebagai gambaran awal kebijakan restrukturisasi yang diperlukan dengan berdasar pada prediksi kinerja keuangan BUMN sektor perikanan awal penggabungan yang telah disusun mencakup tiga strategi yaitu: (i) strategi penajaman fokus bisnis; (ii) strategi perbaikan skala usaha; dan (iii) strategi penciptaan Core Competencies. Pada prinsipnya, ketiga kebijakan tersebut menjadi landasan bagi penyusunan langkah-langkah aksi dan strategis yang kiranya perlu dilaksanakan sebagai berikut :

(I) Langkah aksi yang dimaksud adalah mempertahankan dua unit usaha, yaitu PT PSB dan PT TRM. Sesuai dengan master plan BUMN 2002 - 2006 yang mengharapkan BUMN-BUMN sektor perikanan digabung kedalam dua BUMN di sektor perikanan tangkap dan pengolahan. PT PSB diharapkan di masa depan terfokus pada kegiatan perikanan tangkap sedangkan PT TRM diharapkan terfokus pada kegiatan pengolahan.

Keberadaan BUMN sektor perikanan diperlukan dengan segera karena sangat strategis untuk dipertahankan sebagai acuan bagi pengembangan perusahaan yang berbasis pada sumberdaya alam (perikanan) yang profesional dan berkelas dunia;

(ii) Langkah strategis adalah perbaikan skala usaha dilakukan melalui pemusatan pada lokasi-lokasi atau kantor-kantor cabang yang berlokasi di Indonesia bagian Timur. Hal ini dikaitkan dengan potensi sumberdaya perikanan (SDI), terutama ikan target untuk pasar ekspor, yang masih berpeluang untuk dimanfaatkan sebagai sumber devisa negara. Strategi core competencies dimaksudkan sebagai langkah-langkah perbaikan teknologi penangkapan yang digunakan (oleh PT PSB) dan teknologi pengolahan yang digunakan (oleh PT TRM). Perbaikan teknologi penangkapan diperlukan untuk meningkatkan efisiensi usaha 
penangkapan yang dapat dilihat dari peningkatan CPUE. Perbaikan teknologi pengolahan diperlukan untuk meningkatkan nilai jual produk. Teknologi yang menghasilkan produk-produk derivatif atau turunan menjadi prioritas didalam pemilihan teknologi pengolahan.

\section{KESIMPULAN DAN SARAN}

Kinerja keuangan BUMN sektor perikanan sebelum dan sesudah penggabungan sangat memprihatinkan, namun demikian, keberadaan BUMN di sektor perikanan masih perlu dipertahankan. Hal ini berdasarkan pada arti strategis keberadaan BUMN yang bergerak di sektor yang berbasis pada sumberdaya alam (laut) sebagaimana ditekankan dalam agenda reformasi BUMN yang dinyatakan oleh Kementerian Negara BUMN.

Dua opsi kebijakan yaitu kebijakan penguatan status hukum dan kebijakan prerestrukturisasi diharapkan agar tujuan efisiensi dan efektif di BUMN dapat tercapai. Kebijakan penguatan status hukum perlu segera dilakukan karena hingga tahun 2006 status hukum BUMN sektor Perikanan masih belum jelas, hal ini menjadi hambatan dalam pelaksanaan kegiatan usaha. Kebijakan PreRestrukturisasi merupakan tindak lanjut yang harus segera dilaksanakan oleh direksi yaitu berupa penyusunan neraca penutup dan neraca pembukaan melalui proses audit akuntan, tahapan ini perlu dilakukan untuk mendapatkan gambaran kondisi kesehatan perusahaan.
Dua opsi kebijakan yang disarankan selanjutnya diharapkan menjadi landasan didalam mewujudkan langkah-langkah strategis yaitu: (i) penajaman fokus bisnis; (ii) perbaikan skala usaha; dan (iii) penciptaan Core Competencies.

\section{DAFTAR PUSTAKA}

Balai Besar Riset Sosial Ekonomi. 2006. Indikator Kinerja Sektor Kelautan dan Perikanan. Edisi Revisi dan Updating. Jakarta: BBRSE.

Direktorat Jenderal Peningkatan Kapasitas Kelembagaan dan Pemasaran. 2002. Revitalisasi Aspek Teknis Usaha-Usaha Perikanan. Jakarta: Dirjen PK2P

Hernanto, F. 1998. IImu Usaha Tani. Jakarta: Swadaya. 200-222p

Kementrian Negara Badan Usaha Milik Negara. 2006. Risalah Rapat Umum Pemegang Saham (RUPS) Luar Biasa PT.Perikani (Persero), PT.Tirta Raya Mina (Persero), PT.Perikanan Samodra Besar (Persero) dan PT.Usaha Mina (Persero) tentang Pengesahan Penggabungan Perikani (Persero), PT.Tirta Raya Mina (Persero), PT.Perikanan Samodra Besar (Persero) dan PT.Usaha Mina (Persero) Kedalam PT.Usaha Mina (Persero). Jakarta: Meneg. BUMN

PT. Perikanan Samudra Besar (Persero) . 2004. Laporan Keuangan Untuk Tahun- 